\title{
A competitividade do regadio em Portugal no contexto da Nova Política Agrícola Comum: o caso de uma exploração agrícola no Alentejo
}

Rui Manuel Sousa Fragoso*

Carlos Marques**

Resumo: A Nova Reforma da Política Agrícola Comum (PAC) aprovada em 2003 constitui um reforço dos principais objectivos das reformas anteriores de 1992 e de 2000, como a promoção da competitividade do sector agrícola, da multifuncionalidade dos espaços rurais e agrícolas e da exploração sustentável dos recursos. No essencial, substituem-se as ajudas diretas à produção previstas na maioria dos regulamentos das Organizações Comuns de Mercado, por um regime de pagamento único por exploração sujeito a normas de eco-condicionalidade e a limitações na reconversão dos sistemas de produção agrícola.

Este artigo avalia os impactos da nova PAC na competitividade do regadio em Portugal nas explorações agrícolas do Alentejo, nomeadamente, dos efeitos do pagamento único na afetação e na retribuição dos recursos agrícolas, de modo a identificar as principais alterações nas orientações produtivas e nos rendimentos agrícolas. Também são avaliados alguns dos principais impactos sócio-econômicos e ambientais diretos decorrentes dos ajustamentos produzidos com a Nova PAC.

\footnotetext{
* Professor Auxiliar do Departamento de Gestão de Empresas da Universidade de Évora - Portugal. rfragoso@uevora.pt

**Professor Catedrático do Departamento de Gestão de Empresas da Universidade de Évora - Portugal. cmarques@uevora.pt
} 
A Competitividade do Regadio em Portugal no Contexto da Nova Política Agrícola Comum:

O caso de uma exploração agrícola no Alentejo

A metodologia utilizada baseia-se no desenvolvimento de um modelo micro-econômico de programação matemática estocástica discreta de maximização do valor esperado e de minimização do risco, adaptado às características de uma empresa agrícola do Alentejo. O modelo é utilizado para avaliar prospectivamente o plano de produção e o rendimento no curto e no longo prazo, mediante os cenários da reforma da PAC de 2000 e da Nova Reforma da PAC de 2003.

Palavras-chave: Nova PAC, programação matemática, Alentejo.

Classificação JEL: Q12, Q18, Q15

Abstract: The 2003 Common Agricultural Policy (CAP) reform constitutes a reinforcement of the main objectives of the previous reforms of 1992 and of 2000, namely the promotion of the agricultural competitiveness, the multiple functions of the rural and agricultural areas and the sustainable resource exploitation. The direct production aids in the most Common Market Organizations are replaced by an only payment for each farm, subject to echo-conditionality and limits on the agricultural systems changes.

This article evaluates the impacts of 2003 CAP reform on the Portugal irrigation competitiveness in the Alentejo region farms. The effects of the only payment in the agricultural returns, the main changes in the crop patterns and in the agricultural incomes were studied. They are also appraised direct social economic and environmental impacts of the adjustments produced with the 2003 CAP reform.

The followed methodology is a discreet stochastic programming model. This model maximizes the expected income and minimizes the risk at the farm level. It was used to assess the crop patterns and the farm income in the short and in the long term, in the scenarios of the 2000 CAP and the of the 2003 CAP.

Key words: CAP reform, mathematical programming, Alentejo (region of Portugal).

JEL Classification: Q12, Q18, Q15 


\section{Introdução}

Em Portugal, especialmente nas regiões do Sul, a distribuição das temperaturas e da precipitação ao longo do ano apresenta um padrão climático de influência mediterrânica, caracterizado por verões secos e quentes e por invernos úmidos e temperados. Nestas condições, o regadio permite regularizar a ocorrência da fraca precipitação nos meses em que as temperaturas são mais favoráveis ao desenvolvimento das culturas (maio a setembro), possibilitando aumentar a sua produtividade e alargar o leque de opções produtivas às culturas de Primavera-Verão.

Segundo o Recenseamento Geral Agrícola de 1999 (INE), a superfície irrigável, i.e., potencialmente regada e a superfície efectivamente regada, representavam, respectivamente, cerca de $20 \%$ e de $16 \%$ da superfície agrícola utilizada (SAU) no território português do continente. Em termos do número de explorações agrícolas, a importância do regadio é ainda mais expressiva, uma vez que está presente em cerca de três quartos das explorações do continente.

Marques (1999 e 2004a), na análise do Valor da Produção Agrícola a preços constantes de 1986 e de 1995, identificou os vegetais e hortícolas e os frutos, que em geral são produtos do regadio, como sub-setores dinâmicos da produção agrícola, por apresentarem taxas de crescimento anual superiores à média do sector. Avillez et al. (2004) também refere, com base nos dados do INE, o aumento da produtividade associado às culturas de regadio, em oposição à quebra da produtividade da generalidade das atividades de sequeiro. O mesmo autor argumenta que a importância relativa do regadio e os níveis de competitividade alcançados pelas suas atividades, nos últimos anos têm sido favorecidos pela proteção conferida a alguns produtos no âmbito da Política Agrícola Comum (PAC) e pela política de baixos preços da água praticada até ao presente.

Quando Portugal aderiu à Comunidade Econômica Europeia em 1986, a PAC intervinha principalmente no apoio aos mercados. Os preços eram fixados institucionalmente e eram complementados por subsídios à exportação e por tarifas à importação que protegiam os produtos da Comunidade da concorrência de países terceiros. Neste contexto, a produção agrícola era incentivada pela via dos preços garantidos e os rendimentos agrícolas dependiam dos níveis de preços em vigor e das quantidades produzidas. 
Em 1992 com a aprovação da primeira reforma da PAC (REGs (CEE) 1765 e 1766/92), esta situação alterou-se substancialmente. Nas culturas arvenses (cereais, oleaginosas e proteaginosas) os preços garantidos tendem a ser progressivamente alinhados com os níveis previsíveis no mercado mundial, sendo a redução compensada por pagamentos diretos em função das áreas cultivadas. É criado um sistema obrigatório de retirada de terras de cultivo, também objeto de compensação. Para a carne de bovino são reduzidos os preços de intervenção e os direitos aduaneiros, ao mesmo tempo em que aumentam os valores dos prêmios aos animais. Esta reforma marca na PAC o início do desligamento das ajudas da produção.

Os objetivos de promoção da competitividade, sustentabilidade e multifuncionalidade da agricultura, que orientaram a reforma de 1992, são novamente reforçados em 2000 na segunda reforma da PAC, designada simbolicamente por Agenda 2000.

As negociações no seio da Organização Mundial do Comércio (OMC) e o alargamento da União Europeia (UE) a novos dez Estados Membros, precipitaram em 2003 a aprovação de uma nova reforma da PAC, que representa um novo aprofundamento dos objetivos da reforma de 1992 e reequaciona os meios financeiros de forma mais flexível, na perspectiva da estabilidade orçamental. No que se refere à competitividade, a principal alteração é o desligamento das ajudas através de um regime de pagamento único por exploração (REG (EU) 1782 a 1788/03), que se relaciona direta e indiretamente com as restantes alterações.

A Nova PAC possibilita que cada Estado Membro possa implantar o regime de pagamento único numa base nacional ou regional, apenas aos agricultores que já se beneficiavam anteriormente dos pagamentos diretos ou a todos os agricultores, e total ou parcialmente desligado da produção. Portugal optou pela aplicação parcial do pagamento único a partir de 2005, apenas aos agricultores que já se beneficiavam anteriormente dos pagamentos diretos da Agenda 2000. Nas culturas arvenses o pagamento será completamente desligado da produção e das superfícies cultivadas. Nos ovinos e caprinos o desligamento do prêmio será de $50 \%$, enquanto que nos bovinos se mantém a totalidade do prêmio à vaca aleitante e ao abate de vitelos.

Com a Nova reforma da PAC os agricultores que já se beneficiavam 
das ajudas diretas da Agenda 2000 continuarão a reorientar as suas explorações agrícolas das arvenses para a produção pecuária extensiva e a reconversão para outras opções, em que Portugal apresenta vantagens competitivas, como o olival, os frutos, as horto-frutícolas e as hortoindustriais, poderá estar condicionada, uma vez que a sua realização implica a perda do direito ao pagamento único (Marques, 2004b). Segundo o mesmo autor, o desligamento das ajudas nas culturas arvenses levará a que os agricultores menos competitivos deixem de produzir e que os preços aumentem, mas numa magnitude muito inferior à da perda dos pagamentos diretos.

Este artigo pretende avaliar os impactos da nova PAC na competitividade do regadio nas explorações agrícolas do Alentejo. São estudados os efeitos do pagamento único na afetação e na retribuição dos recursos agrícolas, de modo a identificar as principais alterações nas orientações produtivas e nos rendimentos agrícolas. Também são avaliados alguns dos principais impactos sócio-econômicos e ambientais diretos decorrentes dos ajustamentos produzidos com a Nova PAC.

Para além desta introdução, em que se faz o enquadramento do estudo e se definem o problema e os objectivos, o artigo inclui uma breve análise da evolução e da competitividade das principais culturas de regadio, a metodologia, a apresentação e discussão de resultados e as conclusões.

\section{Evolução e competitividade das principais culturas de regadio}

Na Tabela 1 apresentam-se as explorações com regadio e as áreas das principais culturas regadas no território português do continente e na Região Alentejo.

Em 1999 existiam em Portugal Continental 271,7 mil explorações agrícolas com regadio e foram regados 600 mil ha, o que representa, respectivamente, $71 \%$ do total de explorações e $16 \%$ da superfície agrícola utilizada, e traduz uma área média regada por exploração de 2,2 ha. Relativamente ao Recenseamento Geral Agrícola de 1989, verifica-se uma redução de $40 \%$ no número de explorações com regadio e de $4 \%$ na área regada. A área regada diminui na mesma percentagem da SAU, enquanto que o número de explorações com regadio diminuiu mais do 
que o número total de explorações, o que permite concluir que o aumento da área média regada por exploração de 1,39 para 2,2 ha, não se ficou a dever apenas a investimentos em novos regadios, mas também ao redimensionamento do capital fundiário dessas explorações.

Em 1999, o milho e as culturas forrageiras representavam quase metade da área regada no continente. Apesar do milho ser a cultura de regadio mais representativa, entre 1989 e 1999 a sua área diminuiu 18\% . Também se registaram diminuições significativas nas áreas regadas de prados temporários e de batata.

Tabela 1. Número de explorações com regadio e as áreas das principais culturas regadas no continente e no Alentejo

\begin{tabular}{lrrrrrrrr}
\hline & \multicolumn{3}{c}{ Continente } & \multicolumn{5}{c}{ Alentejo } \\
\cline { 2 - 9 } & 1989 & $\%$ & 1999 & $\%$ & 1989 & $\%$ & 1999 & $\%$ \\
\hline Número total de & 550813 & & 382163 & & 47036 & 35906 & \\
explorações & & & & & & & & \\
Número de explorações & 450279 & & 271719 & & 24253 & & 13998 & \\
com regadio & & & & & & & & \\
Superfície agrícola & 3879602 & & 3736165 & & 1842097 & & 1924044 & \\
utilizada (ha) & 626179 & 100,0 & 600314 & 100,0 & 62547 & 100,0 & 118255 & 100,0 \\
Superfície regada (ha) & & & & & & & & \\
Culturas regadas (ha): & & & & & & & & \\
Trigo duro & 6,1 & 10676 & 1,8 & 36 & 0,1 & 8394 & 7,1 \\
Milho & 177632 & 28,4 & 145500 & 24,2 & 10657 & 17,0 & 22162 & 18,7 \\
Prados temporários & 21482 & 3,4 & 11216 & 1,9 & 1676 & 2,7 & 841 & 0,7 \\
Batata & 70258 & 11,2 & 35351 & 5,9 & 1013 & 1,6 & 685 & 0,6 \\
Beterraba sacarina & 31 & 0,0 & 7423 & 1,2 & 0 & 0,0 & 2899 & 2,5 \\
Girassol & 4566 & 0,7 & 14061 & 2,3 & 2392 & 3,8 & 11418 & 9,7 \\
Culturas forrageiras & 82280 & 13,1 & 135407 & 22,6 & 9425 & 15,1 & 11896 & 10,1 \\
Pomares & 39807 & 6,4 & 31710 & 5,3 & 3787 & 6,1 & 1938 & 1,6 \\
Citrinos & 23734 & 3,8 & 20205 & 3,4 & 3261 & 5,2 & 1928 & 1,6 \\
Vinha & 11575 & 1,8 & 14084 & 2,3 & 154 & 0,2 & 3262 & 2,8 \\
Olival & 6083 & 1,0 & 14085 & 2,3 & 1791 & 2,9 & 7043 & 6,0 \\
Outras culturas & 188129 & 30,0 & 160596 & 26,8 & 28355 & 45,3 & 45789 & 38,7 \\
\hline
\end{tabular}

Fonte: INE, RGA de 1989 e RGA de 1999. 
Em oposição, verificou-se um aumento significativo nas áreas regadas de trigo duro e de girassol, em grande parte motivado pelos elevados montantes dos pagamentos diretos de que essas culturas se beneficiavam no quadro da PAC então em vigor. O forte crescimento da área de beterraba sacarina está associado à instalação de uma fábrica de açúcar em Portugal. O vinho e o olival são culturas tradicionais, que se beneficiaram recentemente de um grande desenvolvimento tecnológico e do reposicionamento dos seus produtos nos mercados numa ótica de valor.

A Região Alentejo, situada a Sul do Rio Tejo e a Norte da Região Algarve, representa praticamente um terço do território português do continente. Em 1999, esta região detinha no país 5\% das explorações, $9 \%$ das explorações com regadio, metade da SAU e um quinto da superfície regada. Estas percentagens traduzem dimensões médias das explorações (53 ha) e da área regada (8,5 ha) muito acima da média do continente. A dimensão média das explorações no Alentejo cresceu na década de 1990 da mesma forma que no continente, no entanto o ritmo de crescimento da área regada foi o dobro.

Em 1999, as principais culturas regadas no Alentejo também foram o milho $(18,7 \%)$ e as culturas forrageiras (10,1\%). Entre 1989 e 1999 as áreas regadas de milho, trigo duro, girassol, culturas forrageiras, vinha e olival não só registaram aumentos assinaláveis, como também foram mais acentuados do que no continente. Aqui mais uma vez se verifica, e de forma ainda mais acentuada, que foi nas culturas que mais se beneficiaram da PAC que se registraram os maiores crescimentos da área regada.

Na Tabela 2 apresentam-se para as principais atividades agrícolas do Alentejo, a produtividade média da terra, o valor da produção agrícola e dos custos, os rácios valor da produção/benefícios, subsídios/benefícios, benefícios/custos e valor da produção/custos e ainda os níveis de utilização de água e de mão-de-obra.

As culturas de regadio apresentam valores de produtividade média da terra e da produção agrícola muito superiores aos das culturas de sequeiro. Por exemplo, a produtividade média da terra nas hortofrutícolas e industriais e nos frutos é superior em 10 a 20 vezes à das arvenses de sequeiro. Os custos de produção também são substancialmente superiores nas culturas de regadio e traduzem níveis mais elevados de investimento agrícola e de distribuição de rendimento 
A Competitividade do Regadio em Portugal no Contexto da Nova Política Agrícola Comum: O caso de uma exploração agrícola no Alentejo

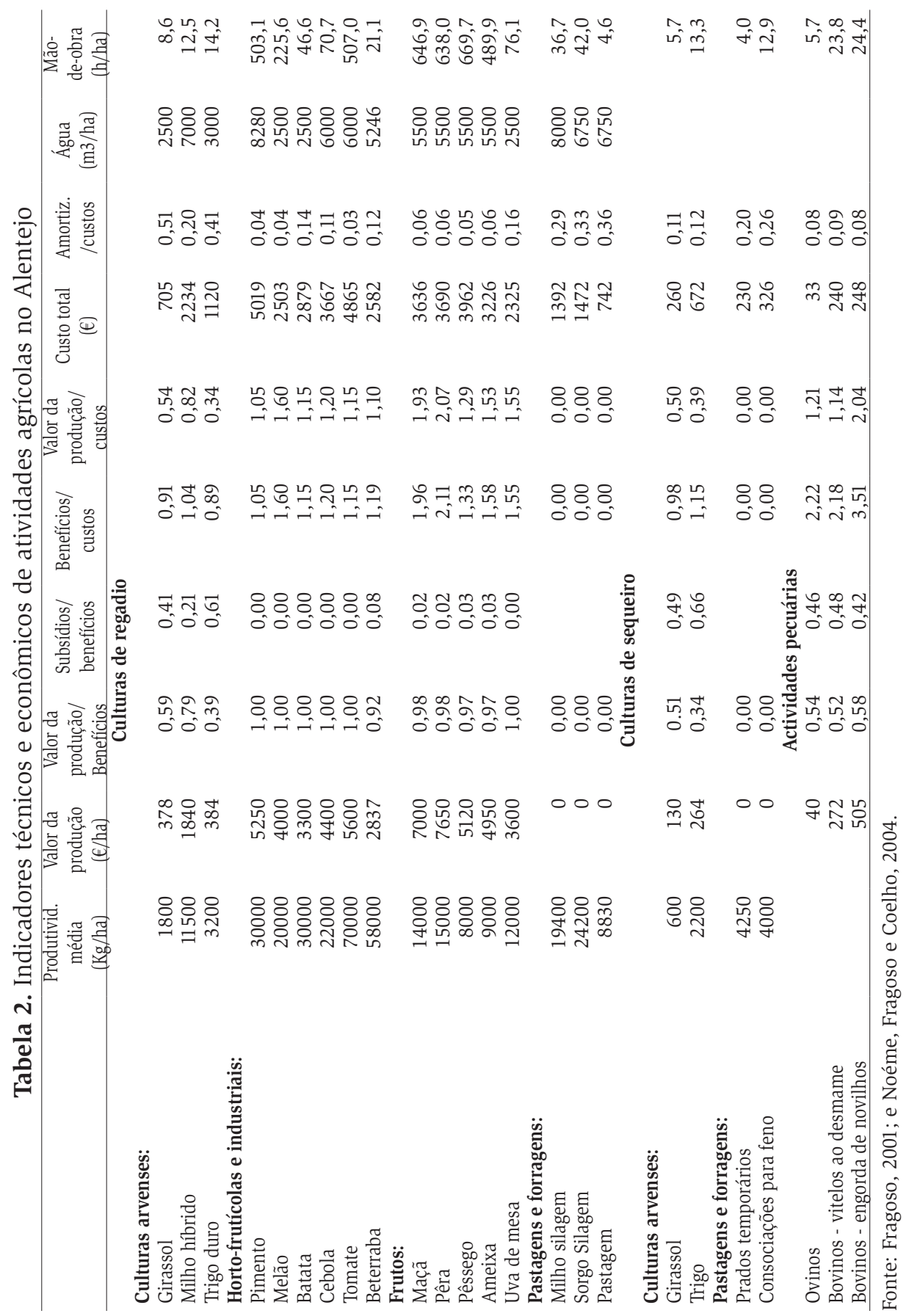


através das atividades econômicas que prestam serviços à agricultura e do emprego agrícola.

Nas culturas arvenses, uma parte importante dos benefícios provêm das ajudas diretas. No caso do trigo duro a componente das ajudas é mais de $50 \%$ do total dos benefícios. No girassol essa percentagem é de $41 \%$ no regadio e de $50 \%$ no sequeiro. Contrariamente, o milho é, das culturas arvenses, a que apresenta o menor peso relativo das ajudas nos benefícios totais. Nos grupos das horto-frutícolas e industriais e dos frutos, os benefícios provêm quase exclusivamente do valor da produção, i.e., da valorização da produção a preços de mercado. Apenas os frutos se beneficiam de uma ajuda à protecção integrada no âmbito do Programa de Desenvolvimento Rural de Portugal Continental (RURIS). Nas actividades pecuárias os benefícios também são fortemente influenciados pelos prêmios aos animais, que representam nos bovinos de carne e nos ovinos mais de $40 \%$ do total.

A retribuição dos recursos foi avaliada na ótica privada através do rácio benefício/custo e na ótica social através do rácio valor da produção/custo. No primeiro caso as culturas arvenses de sequeiro e de regadio apresentam valores próximos do limiar da rendibilidade $(0,89$ a $1,15 € / €)$, sendo em alguns casos inferiores. Neste tipo de culturas quando se avalia a retribuição na ótica social, em que são retirados dos benefícios os subsídios, verifica-se que os custos ultrapassam claramente os benefícios, variando o rácio do valor da produção/custos entre $0,34 € / €$ no girassol de regadio e $0.82 € / €$ no milho. Estes resultados permitem antecipar no quadro da Nova PAC uma forte perda de competitividade das culturas arvenses.

As horto-frutícolas e industriais e os frutos apresentam elevados retornos, tanto na ótica social, como na ótica privada. No primeiro caso o rácio benefício/custo varia entre $1,05 € / €$ no pimento e 1,6 €/€ no melão. No segundo caso, os valores são ainda superiores e situam-se entre $1,33 € / €$ no pêssego e $2,11 € / €$ na pêra. Nessas actividades, o rácio valor da produção/custo aproxima-se do rácio benefício/custo. Um completo desligamento das ajudas à produção não afeta a competitividade, nem são de esperar impactos no rendimento decorrentes da Nova PAC. No entanto, os beneficiários do pagamento único que pretendam reconverter as suas áreas de culturas arvenses para horto-frutícolas e 
industrais ou para frutos, perderão o direito a esse pagamento na mesma proporção da área reconvertida.

De um modo geral, as culturas mais competitivas do ponto de vista econômico são também as mais exigentes em água e mão-de-obra. Nas horto-frutícolas e industriais e nos frutos as necessidades de água são relativamente elevadas e aproximam-se das do milho (7000 m3/ha). No que diz respeito à mão-de-obra, é frequente encontrarem-se, nesses dois grupos, culturas com necessidades anuais superiores às 400 h/ha, o que é manifestamente superior às $14 \mathrm{~h} /$ ha necessárias no milho.

As horto-frutícolas e industriais e os frutos, apesar de financeiramente interessantes, requerem grandes quantidades de água, mão-deobra e capital, que associadas aos elevados riscos tecnológicos e de comercialização, tornam-nas acessíveis apenas a uma franja limitada de agricultores bem preparados com acesso ao capital, aos mercados e com boa capacitação nas áreas técnica e de gestão. 


\section{Metodologia}

A metodologia utilizada baseou-se no desenvolvimento de um modelo micro-econômico de programação matemática estocástica discreta de maximização do valor esperado e de minimização do risco, adaptado às características de uma empresa agrícola do Alentejo. Esta metodologia é muito útil para avaliar os impactos das novas políticas na economia ou nas empresas. Para o Alentejo, são já numerosos os trabalhos de investigação que abordam o problema da análise prospectiva dos efeitos das políticas agrícola e econômica recorrendo à programação matemática. Entre os mais relevantes referem-se Marques (1988 e 1994), Carvalho (1994), Lucas (1995), Henriques (1995), Godinho (1997) e Fragoso (1996 e 2001).

A aplicação de modelos econômicos de programação matemática aos problemas do planeamento agrícola deve ter em conta as características particulares das empresas, nomeadamente, a modelação de factores naturais, técnicos, institucionais e econômicos. Segundo Hazell et Norton (1986), a conjugação desses aspectos determina os resultados econômicos dos sistemas de produção disponíveis, as decisões dos empresários agrícolas e a estrutura das suas empresas. No caso das empresas agrícolas do Alentejo, a aplicação das medidas da PAC, as condições dos mercados do produto e do fator, a heterogeneidade dos recursos, a sazonalidade das produções e da procura de recursos, a interdependência das produções e a sua variabilidade, são os principais aspectos que devem ser incluídos na formulação de um problema de programação matemática.

A PAC e as condições de mercado, através dos níveis de preço e das ajudas em vigor, traduzem o ambiente sócio-econômico em que a empresa opera. A heterogeneidade dos recursos, como os solos com diferentes produtividades, determina o sistema de produção a adotar (Marques, 1992). A dependência climática das atividades de produção vegetal confere aos seus itinerários técnicos uma marcada sazonalidade na procura de recursos, sendo por isso necessário mobilizar uma grande parte dos recursos da empresa em períodos de tempo relativamente curtos, como acontece nas épocas de colheita e de sementeira. A interdependência das produções ocorre principalmente na produção 
A Competitividade do Regadio em Portugal no Contexto da Nova Política Agrícola Comum:

O caso de uma exploração agrícola no Alentejo

de pastagens e de forragens e no aproveitamento dos sub-produtos (palhas) e dos resíduos (restolho) dos cereais na alimentação dos animais, constituindo esses produtos simultaneamente um output das atividades vegetais e um input das atividades pecuárias.

No Alentejo, a variabilidade da produção e do rendimento agrícola deve-se principalmente à distribuição irregular da precipitação entre anos, que condiciona a utilização dos fatores de produção, como a mão-de-obra, tração e água para as culturas de regadio, e faz variar fortemente as quantidades produzidas de produtos para venda e para a auto-utilização e, por conseguinte, o rendimento dos agricultores. $\mathrm{Na}$ variabilidade da disponibilidade de água para rega, deve-se considerar simultaneamente o efeito da precipitação irregular e o efeito de regularização das infra-estruturas de armazenamento (albufeiras, barragens e aquíferos), uma vez que os efeitos da falta de água se fazem sentir a mais longo prazo do que os efeitos nas quantidades produzidas e nas condições de utilização dos fatores.

Outro aspecto a ter conta na variabilidade do rendimento nas empresas agrícolas do Alentejo é a flutuação dos preços de alguns produtos nos mercados, especialmente nas culturas de regadio dos subsetores dos frutos e das horto-frutícolas.

Os modelos estocásticos de programação matemática são muito úteis para tratar a variabilidade do rendimento nas empresas agrícolas, por permitirem incorporar o risco relativo à incerteza da disponibilidade de recursos e o ajustamento dos coeficientes input-output em função dos estados do sistema (Hardaker et al., 1997). A programação estocástica discreta sugerida por Cocks e desenvolvida posteriormente por Rae (1971), consegue reproduzir com mais rigor o processo de tomada de decisão do empresário agrícola, uma vez que os coeficientes técnicos das atividades podem ser ajustados em função da procura e da disponibilidade dos recursos nos respectivos estados de decisão. Este tipo de modelos, se a função objectivo for adequada, capta adequadamente o custo de produção nos regadios do Alentejo. Burt et Stauber (1971) foram os primeiros a incluir como critério de decisão a minimização da variabilidade dos benefícios e a maximização dos benefícios esperados. Posteriormente vários autores utilizaram procedimentos similares, como é caso de Boussard 
et al. (1997) para estudar os efeitos da primeira reforma da PAC em explorações produtoras de cereais em França.

O modelo de programação matemática desenvolvido no âmbito deste artigo baseia-se em Fragoso (1996 e 2001), Jacquet et Pluvinage (1997), Keplinger et al. (1998) e Blanco (1999) e sua formulação simplificada é a seguinte:

$\operatorname{Max} Z=\sum_{j} V L_{j} \cdot X_{j}+\sum_{p c} V L_{p c} \cdot X_{p c}-p h i \cdot \sum_{s} \Sigma_{s p} p_{s} \cdot D V_{s, s p}$

s.a. $X_{j}=p_{s} \cdot Y_{j, s}$

$\sum_{j}\left(V L_{j, s p}-V L_{j}\right) \cdot Y_{j, s}+\sum_{p c}\left(V L_{p c, s p}-V L_{p c}\right) \cdot X_{p c}+D V_{s, s p} \geq 0$

$\sum_{j} Y_{j, s} \leq S$

$\sum_{j} a_{j} Y_{j, s} \leq q_{s}$

$\sum_{j} Y_{j p, s} \cdot Q T_{j p, p a} \geq N A_{p c, p a} \cdot X_{p c}$

$X_{j} \geq 0 ; X_{p c} \geq 0 ; Y_{j, s} \geq 0 ; D V_{j} \geq 0$;

onde: $X_{j}$, e $Y_{j, s}$ são, respectivamente as variáveis de decisão relativas à área (ha) esperada da cultura $j$ e à área da cultura $j$ no estado de natureza da dispon ibilidade de água $s$; $X_{p c}$ é a variável que determina a dimensão ótima do efetivo pecuário $p c$ (unidades pecuárias); $D V_{j}$ é a variável que contabiliza os desvios negativos do rendimento em cada estado de natureza da disponibilidade de água $s$ e de mercado $s p ; p_{s}$ é a probabilidade de ocorrência dos estados de natureza $s$; phi é uma aproximação do coeficiente de aversão relativa ao risco; $V L$ são os rendimentos das atividades de produção vegetal $j$ e de produção pecuária $p c$; $\mathrm{S}$ são os fatores fixos da empresa, terra e investimentos de longo prazo; $a_{j}$ são os coeficientes técnicos das atividades em cada estado de natureza $s$; $q_{s}$ é disponibilidade ou o uso dos fatores ajustáveis em cada estado de natureza $s ; Q T_{j p, p a}$ e $N A_{p c, p a}$ são respectivamente os coeficientes técnicos de valorização dos alimentos produzidos pela cultura jp no período do ano pa e as necessidades alimentares dos animais do efetivo $p c$ no período $p a$.

A função objectivo considera simultaneamente como critérios de decisão a maximização do rendimento esperado e a minimização dos desvios 
A Competitividade do Regadio em Portugal no Contexto da Nova Política Agrícola Comum:

O caso de uma exploração agrícola no Alentejo

negativos do rendimento (1). Consoante se trate de uma simulação de curto ou de longo o rendimento é dado pelo cashflow anual ou pelo valor líquido anual (VLA). No primeiro caso calcula-se a retribuição para os fatores terra, empresário e capital fixo de exploração, e no segundo caso apenas para a terra e para o empresário. A maximização do valor desta função está sujeita às restrições do aparelho de produção (4) e de uso de recursos ou fatores ajustáveis em função da disponibilidade de água (5) e (6). No primeiro caso, incluiu-se o capital fundiário dividido em terra agrícola e terra irrigável e o capital de exploração fixo (equipamentos de rega e efectivos pecuários). O segundo caso diz respeito à utilização da água, da mão-de-obra e da tração e por períodos do calendário cultural e do balanço forrageiro por período crítico da alimentação dos animais (ver Fragoso, 2001). O balanço forrageiro foi estabelecido para os períodos críticos de crescimento das pastagens e forragens em termos das disponibilidades e necessidades alimentares de energia metabolizável, proteína bruta digestível e capacidade máxima de ingestão.

A solução do modelo prescreve os ajustamentos no plano e no aparelho de produção em função das expectativas dos preços dos produtos nos mercados agrícolas, e da disponibilidade de água em cada estado de natureza. Para cada estado de natureza o modelo apresenta uma solução ajustada à disponibilidade de água. É com base nesses resultados, que traduzem as consequências das diversas situações de risco, e na probabilidade de ocorrência dos estados de natureza que o empresário decide acerca do plano de produção e dos investimentos agrícolas.

\section{Resultados}

Nas Tabelas 3 e 4 apresentam-se, respectivamente, os resultados de calibração e os resultados das simulações efetuadas para os cenários da PAC de 2000 e da PAC de 2003.

O primeiro objectivo na obtenção de resultados foi verificar a aderência do modelo com a realidade observada e proceder à escolha do coeficiente apropriado de aversão ao risco. Depois realizam-se duas simulações para cada cenário de política agrícola (PAC 2000 e PAC 2003), uma de curto prazo e outra de longo prazo. Por último, no contexto do cenário da PAC de 
2003 foram incluídas no modelo novas alternativas de investimento agrícola e foram obtidos resultados para três níveis de preço da água $(0,02,0,06$ e $0,1 € / \mathrm{m} 3$ ). De acordo com os objetivos do artigo, a análise dos resultados incidiu nas alterações do comportamento dos agricultores, do rendimento agrícola e nos impactos diretos sócio-econômicos e ambientais.

Para calibrar o modelo começou-se por parametrizar o coeficiente de aversão ao risco (phi). Considerando um valor nulo para esse coeficiente, que traduz uma atitude neutral ao risco, a solução do modelo aponta claramente para uma especialização na produção de bovinos de carne e de pastagens e forragens. Apesar destes resultados apresentarem desvios consideráveis em relação à situação de referência, refletem a tendência dos ajustamentos que ocorreram nas grandes explorações agrícolas do Alentejo nos últimos anos. Quando se aumenta o valor de phi para 0,7 e para 1,1, assumindo um comportamento mais adverso ao risco, a solução do modelo aproxima-se mais da realidade observada na situação de referência. Para um phi de 1,1 o modelo reproduz com grande exatidão o plano de exploração da situação de referência, no entanto a sua resposta é fraca às alterações da PAC e à introdução de investimentos agrícolas alternativos. Por essa razão, considerou-se para a realização das simulações um phi de 0.7 .

Tabela 3. Resultados de calibração do modelo de programação matemática

\begin{tabular}{|c|c|c|c|c|}
\hline & \multirow{2}{*}{$\begin{array}{c}\text { Situação de } \\
\text { referência }\end{array}$} & \multicolumn{3}{|c|}{ Modelo } \\
\hline & & $\mathrm{PHI}=0$ & $\mathrm{PHI}=0,7$ & $\mathrm{PHI}=1,1$ \\
\hline \multicolumn{5}{|c|}{ Atividades vegetais (ha) } \\
\hline Superfície agrícola utilizada (SAU) & 309,5 & 310,0 & 310,2 & 310,0 \\
\hline Superfície regada & 57 & 44,6 & 54,5 & 55,1 \\
\hline Girassol & 4,9 & & & 4,9 \\
\hline Trigo duro & 15,8 & & 15,6 & 15,8 \\
\hline Beterraba & 8,9 & & 8,9 & 8,9 \\
\hline Milho grão & 27,4 & & 25,3 & 25,5 \\
\hline Silagem de sorgo & & 44,6 & 4,7 & \\
\hline Superfície de sequeiro & 252,5 & 265,4 & 255,7 & 254,9 \\
\hline Trigo duro & 27,6 & 27,6 & 27,6 & 27,6 \\
\hline Consociação para feno & 15 & 21,6 & 4,5 & 10,1 \\
\hline Prados temporários & 23,4 & 214,8 & 48,1 & 22,3 \\
\hline Pastagens permanentes & 181,9 & & 171,9 & 191,0 \\
\hline Pousio obrigatório & 4,6 & 1,5 & 3,6 & 3,9 \\
\hline \multicolumn{5}{|c|}{ Atividades pecuárias (unidade pecuária) } \\
\hline Bovinos de carne & 50 & 339 & 82 & 45 \\
\hline Desvio negativo $(€ /$ ha) & & 398 & 96,3 & 52,8 \\
\hline
\end{tabular}

Fonte: Resultados do modelo e dados de inquéritos aos produtores. 
A Competitividade do Regadio em Portugal no Contexto da Nova Política Agrícola Comum: O caso de uma exploração agrícola no Alentejo

No cenário da PAC de 2000, na situação de curto prazo, a superfície regada representa $17,5 \%$ da SAU e é aproveitada por ordem decrescente com culturas arvenses $(13,2 \%)$, horto-industriais $(2,9 \%)$ e por pastagens e forragens $(1,5 \%)$. Na superfície de sequeiro as pastagens e forragens ocupam $72,4 \%$ da SAU e as culturas arvenses $8,9 \%$.

No longo prazo verifica-se o abandono das arvenses de regadio e o reforço das pastagens e forragens de sequeiro e de regadio e, por conseguinte, o aumento do número de unidades pecuárias de bovinos de 82 para 97. Com o cenário da Nova PAC 2003, as culturas arvenses, tanto no sequeiro como no regadio, deixam de ser uma opção viável e é de esperar acréscimos na produção pecuária e de pastagens e forragens. Na situação de longo prazo, o número de unidades pecuárias de bovinos aumenta para 107 e a área de pastagens e forragens sobe para 3,1\% da SAU no regadio e para $94 \%$ da SAU no sequeiro.

Apesar da nova PAC de 2003 conduzir à extensificação da produção, os rendimentos aumentam cerca de $24 \%$ no curto prazo e quase que duplicam quando se compara as situações de longo prazo dos dois cenários. Nos proveitos é de esperar uma diminuição de cerca de 30\% no curto prazo e um aumento de $18 \%$ relativamente à situação de longo prazo. Em ambos os casos se verifica o decréscimo do valor da produção (47 e 4\%), que é compensado pelo aumento dos subsídios (3 e $52 \%$ ) e pela diminuição dos custos de produção (44 e $11 \%$ ).

Os rendimentos agrícolas não deverão diminuir com a Nova PAC, mas é de se prever a diminuição do contributo econômico da agricultura. Há uma clara diminuição da importância do valor da produção na procura dos rendimentos agrícolas e uma deterioração das relações comerciais com os outros sectores, como a indústria e o comércio de fatores de produção e serviços especializados.

No que diz respeito aos impactos ambientais, a Nova PAC promove alguns benefícios diretos, como a manutenção das cargas pecuárias, a diminuição do consumo de água por hectare irrigável para $1.628 \mathrm{~m} 3$ no curto prazo e para $1.940 \mathrm{~m} 3$ no longo prazo, e a redução do uso de combustíveis, lubrificantes, energia e agro-químicos para um quarto e três quartos dos níveis registados no cenário da PAC de 2000.

A introdução de investimentos alternativos em culturas dos subsetores das horto-frutícolas e industriais e dos frutos altera substancial 


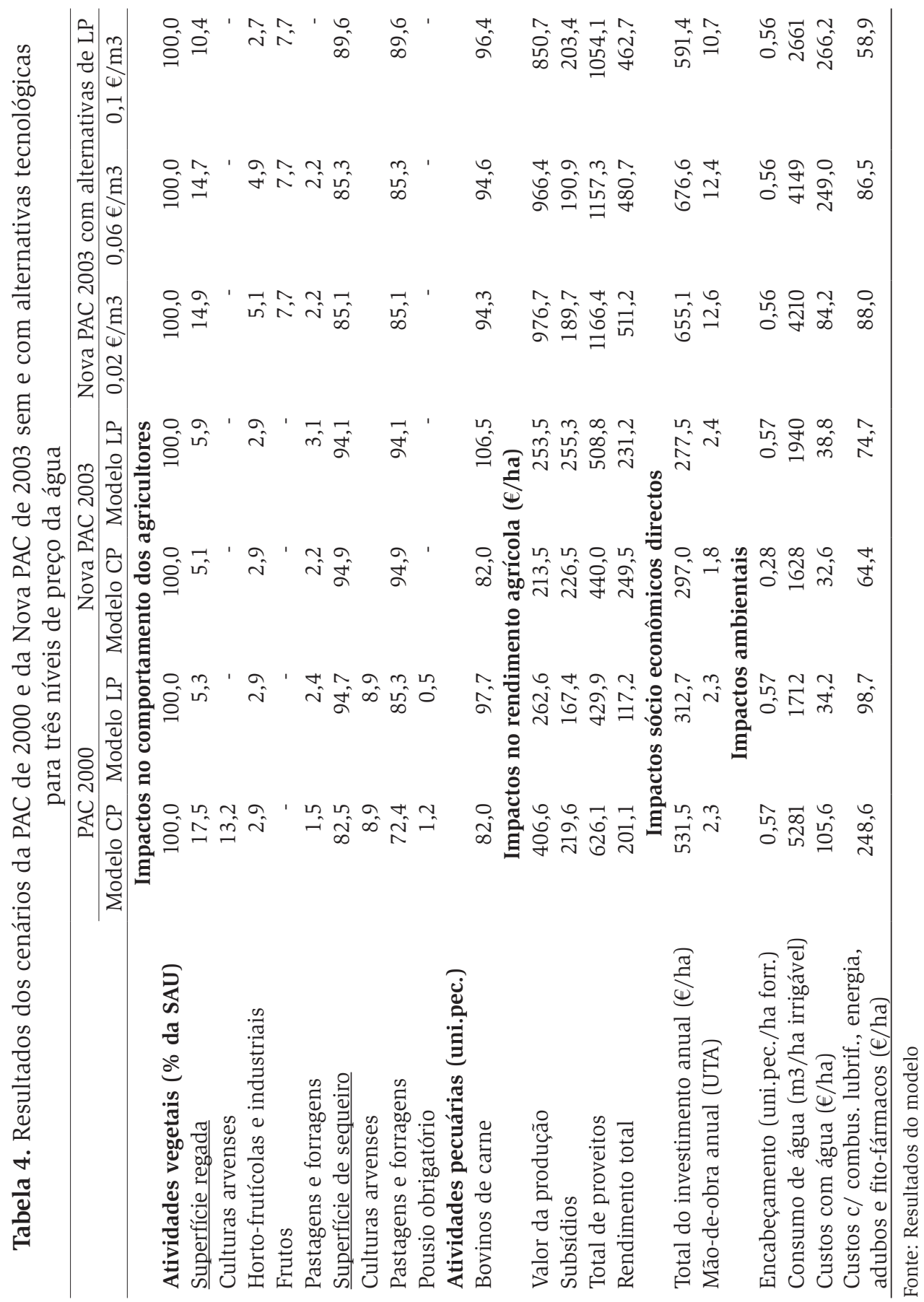


A Competitividade do Regadio em Portugal no Contexto da Nova Política Agrícola Comum:

O caso de uma exploração agrícola no Alentejo

mente os resultados do modelo, tanto no que diz respeito ao comportamento dos agricultores como aos impactos sócio-econômicos diretos. Para os níveis de preço da água de 0,02, 0,06 e 0,1€/m3, cerca de 10 a $15 \%$ da SAU é explorada em regime de regadio com frutos $(7,7 \%)$, horto-frutícolas $(2,7$ a $5,1 \%)$ e pastagens e forragens. As pastagens e forragens de sequeiro representam 85 a $89 \%$ da SAU e a dimensão do efetivo de bovinos é de 94 a 96 unidades pecuárias.

A adopção desses investimentos agrícolas permite quadruplicar os rendimentos agrícolas principalmente a partir do valor da produção, que praticamente triplica. O aumento dos proveitos é acompanhado da duplicação do investimento agrícola e de um aumento do emprego agrícola de 2,3 para 10,7 a 12,6 unidades de trabalho anual. Esses impactos refletem benefícios sócio-econômicos diretos e o reforço da competitividade do regadio.

Contrariamente ao que seria de se esperar, os resultados não refletem um acréscimo substancial dos impactos ambientais diretos. Apesar de aumentar o consumo de água por hectare irrigável, relativamente ao cenário da PAC de 2000, de $1.712 \mathrm{~m} 3$ para 2.661 a $4.210 \mathrm{~m} 3$, a utilização de combustíveis, lubrificantes, energia e agro-químicos é ainda assim inferior. Esta melhoria nos impactos ambientais está associada à utilização de maquinaria agrícola mais ligeira, o que alivia o uso de combustíveis, lubrificantes e energia, e de tecnologias de produção integrada na produção de frutos, que fazem um uso limitado de agro-químicos.

\section{Conclusões}

Neste artigo avaliam-se os impactos da nova PAC na competitividade do regadio nas explorações agrícolas do Alentejo. O principal objetivo consiste em determinar a direção e a magnitude dos efeitos do pagamento único na afetação e na retribuição dos recursos agrícolas. Avaliam-se as principais alterações nas orientações produtivas e nos rendimentos agrícolas e os principais impactos sócio-econômicos e ambientais diretos decorrentes dos ajustamentos produzidos, com base num modelo micro-econômico de programação matemática estocástica discreta de maximização do valor esperado e de minimização do risco, adaptado às características de uma empresa agrícola do Alentejo. 
Os resultados do modelo permitem concluir que as culturas arvenses deixarão de ser competitivas no contexto da Nova PAC. As suas áreas deverão ser substituídas, tanto no sequeiro como no regadio, por pastagens e forragens para o reforço da produção de bovinos de carne. Os rendimentos agrícolas deverão manter-se ou até mesmo crescer, uma vez que o desligamento das ajudas permite uma afetação dos recursos mais racional do ponto de vista econômico, baseada na rentabilidade das atividades e na retribuição dos recursos. O produtor deverá abandonar as atividades que não são competitivas na ótica social e cuja rentabilidade dependia dos pagamentos diretos, reduzindo assim os custos de produção ao mesmo tempo que se beneficia do pagamento único.

Apesar de ser esperada a manutenção ou até mesmo algum acréscimo de rendimento, a importância do regadio na procura desse rendimento diminui substancialmente, em virtude da maioria dos proveitos passarem a ser provenientes do pagamento único e dos prêmios das atividades pecuárias. Paralelamente, é inevitável que se verifique um decréscimo do investimento agrícola com consequências diretas e indiretas no desenvolvimento das comunidades rurais. É ainda de referir que os efeitos decorrentes da Nova PAC se traduzem em impactos ambientais benéficos, na medida em que se reduz o consumo agrícola de água, de combustíveis, lubrificantes e energia e de agro-químicos.

A introdução de investimentos alternativos em culturas dos subsectores das horto-frutícolas e industriais e dos frutos altera substancialmente o comportamento dos agricultores e os impactos sócio-econômicos diretos da Nova PAC. Perante este cenário de política agrícola, essas alternativas mostram-se competitivas, permitindo não só o aproveitamento das infra-estruturas de regadio já existentes, como aumentar para patamares bastante superiores os rendimentos agrícolas, o valor da produção e o investimento agrícola, e, por conseguinte a contribuição econômica do setor. Tudo isso, mantendo a utilização de combustíveis, lubrificantes e energia e de agro-químicos a níveis ligeiramente inferiores aos que actualmente se verificam com a Agenda 2000.

A realização de investimentos agrícolas nos subsectores das hortofrutícolas e industriais e dos frutos, poderá contrariar alguns dos efeitos negativos da Nova PAC na competitividade do regadio. No entanto, a complexidade tecnológica desses investimentos, as elevadas exigências 
em capital e mão-de-obra, associadas a uma maior expectativa da possibilidade de perdas de rendimento, poderão levar a que a reconversão agrícola seja limitada a um grupo de agricultores empresários bem preparados e empreendedores.

\section{Referências bibliográficas}

AVILLEZ, F.; SILVA, F.G.; et MARTINS, V. Preço da água e rentabilidade da agricultura de regadio em Portugal: metodologia para cálculo do impacto da Reforma da PAC e da aplicação da Directiva Quadro da Água. In: IV Congresso Nacional de Economistas Agrícolas. Faro, 2004.

BLANCO, M.F. La Economía del Agua: Análisis de Políticas de Modernización y Mejora de Regadios en España. Madrid, Tesis doctoral - Universidad Politécnica de Madrid, 1999.

BOUSSARD, J.M.; BOUSSEMART, J.P.; FLICMAN, G. ; JACQUET, F. ; et LEFER, H.B. Les effets de la réforme de la PAC sur les exploitations de grande culture. Économie Rural, 239, Mai-Jun, 1997.

BURT, O.R.; et STAUBER, M.S. Economic Analisys of Irrigation in Subhumid Climate. American Journal of Agricultural Economics, 53, pp. 22-46, 1971.

CARVALHO, M.L.P.M.V.S. Efeitos da Variabilidade das Produções Vegetais na Produção Pecuária Aplicação em Explorações Agro-Pecuárias do Alentejo: Situações Actual e Decorrente da Nova PAC. Évora, 1994. Dissertação de Doutoramento - Universidade de Évora.

FRAGOSO, R.M.S. Avaliação dos Impactos Sócio-Económicos do Plano de Rega de Alqueva no Sector Agrícola do Alentejo: O caso do bloco de rega da infra-estrutura 12. Évora, 2001. Dissertação de Doutoramento - Universidade de Évora.

FRAGOSO, R.M.S. Évaluation des impacts socio-économiques du développement de l'irrigation: le cas de l'agriculture dans la région de l'Alentejo. Montpellier, CIHEAM-IAMM, 1997. Collection de Thèses et Masters IAMM, n. ${ }^{\circ} 40$,.

GODINHO, L. The Impact of 1992 CAP Reform on Soil Erosion in the 
Alentejo Region of Portugal. London, 1997. Ph.D. Dissertation - Wye College, University of London.

HARDAKER, J.B.; HUIRNE, R.B.M.; et ANDERSON, J.R. Coping with Risk in Agriculture. Wallingford, CAB International, 1997.

HAZELL, P.B.R.; et NORTON, R.D. Mathematical Programming for Economic Analysis in Agriculture. New York., Mac Millan Publishing Company, 1986.

HENRIQUES, P.D.S. Technical Efficiency and Changes in Alentejan Farming Systems. Reading, 1995. PhD. Dissertation - University of Reading. INE - INSTITUTO NACIONAL DE ESTATÍSTICA. Recenseamento Geral Agrícola - RGA, 1989.

INE - INSTITUTO NACIONAL DE ESTATÍSTICA. Recenseamento Geral Agrícola - RGA, 1999.

JACQUET, F.; PLUVINAGE, J. Climatic Uncertainty and Farm Policy: A Discrete Stochasting Programming Model for Cereal-Livestock Farms in Algeria. Agricultural Systems, 53, pp. 387-407, 1997.

KEPLINGER, K.O.; MCCARL, B.A.; CHOWDHURY, M.E.; et LACEWELL, R.D. Economic and Hydrologic Implications of Suspending Irrigation in Dry Years. Journal Agricultural and Resource Economics, 23, pp. 191-205, 1998.

LUCAS, M.R.V. A Competitividade da Produção de Borrego no Alentejo. Évora, 1995 Dissertação de Doutoramento - Universidade de Évora.

MARQUES, C.A.F. Portuguese Entrance into the European Comunity: Implications for Dry Land Agriculture in the Alentejo Region. West Lafayette Indiana, 1988. Ph.D. Dissertation, Purdue University.

MARQUES, C.A.F. Implementações Empíricas Base de Modelos de Programação Linear de Empresas Representativas do Alentejo. Évora, Universidade de Évora - Anais da Universidade de Évora, 1992.

MARQUES, C.A.F.; FRAGOSO, R.M.S.; NETO, M.C.; SERRALHEIRO, R.; SANTOS, L. Analysis of Socio-Economic Impacts of Agricultural Policy Reform in Certain European Regions: Competitiviness and Environmental 
Protection. Évora, Universidade de Évora, Portuguese Team Final Report of European Community Comission contract No. 8001-CT91-306, 1994.

MARQUES, C.A.F. Evolução da Agricultura Portuguesa no seio da Política Agrícola Comum Europeia. Congresso SOBER. Brazil, 1999.

MARQUES, C.A.F. A Agricultura Portuguesa face à Política Agrícola Comum. In: IV Congresso Nacional de Economistas Agrícolas, Faro, 2004a. MARQUES, C.A.F. A Aplicação do Sistema de Pagamento Único da PAC em Portugal. In: Congresso Internacional sobre la Política Agrária Comunitária, Cáceres, Espanha, 2004b.

NOÉME, C.; FRAGOSO, R. et COELHO, L. Avaliação económica da utilização da água em Portugal - Determinação do preço da água para fins agrícolas: Aplicação nos Aproveitamentos Hidro-Agrícolas de Odivelas, da Vigia e do Sotavento Algarvio. Lisboa, Instituto Superior de Agronomia, estudo realizado para o Ministério da Agricultura e do Desenvolvimento Rural, IDRHa, 2004.

RAE, A.N. An empirical application and evaluation of discrete stochastic programming in farm management. American Journal of Agricultural Economics, 53, pp. 625-638, 1971.

REGULAMENTOS (CEE) No 1765/92 e 1766/92. Jornal Oficial das Comunidades Europeias ${ }^{\circ}$ L 181 de 1.7.92, pp. 12-39.

REGULAMENTOS (CE) No 1782/03 a 1788/03. Jornal Oficial das Comunidades Europeias n ${ }^{\circ}$ L 270 de 21.10.2003, pp. 1-69.

Recebido em dezembro de 2005 e revisto em setembro de 2006. 